\title{
Arctic Climate Insulation Systems
}

\author{
Nina Umnyakova ${ }^{1}$, Igor Bessonov ${ }^{1}$, Alex Zhukov², and Ekaterina Zinoveva ${ }^{2, *}$ \\ ${ }^{1}$ NIISF RAASN, Lokomotivny passage, 21, Moscow, Russia \\ ${ }^{2}$ NRU MGSU, Yaroslavl highway, 26, Moscow, Russia
}

\begin{abstract}
The article describes the features of the implementation of insulation systems in extreme climatic conditions, including in conditions of significant negative and alternating temperatures, high wind speeds and more. It is noted that the adaptation of building systems to similar operating conditions places special demands on heat-insulating materials, as well as resistance to mechanical and climatic influences, vapor permeability, and stability of properties for the entire period of operation. Taking into account the temperature regime of the polar territories, it becomes necessary to develop special solutions for the creation of insulating shells that have high heat engineering uniformity and durability, as well as those that are resistant to very negative and alternating temperatures. Also important is the heat, moisture, and vapor barrier properties of these systems. Taking into account the operational features of the polar territories, three main groups of objects requiring complex isolation and protection can be distinguished: residential buildings, roads on permafrost, modular buildings and residential capsules of mobile equipment. The article considers the feasibility of implementing such heatefficient systems using foamed plastics, namely products based on extruded polystyrene foam and foamed polyethylene. Solutions are proposed for the implementation of overlaps over ventilated cellars, insulation of walls, roads and mobile structures.
\end{abstract}

\section{Introduction}

The development of the northern territories is relevant for the development of all countries bordering the Arctic regions. For Russia, these regions are of particular importance in view of the advisability of developing the Northern Sea Route, increasing the country's defense, exploration and production of oil and gas on the shelf of the northern seas, as well as the extraction of other minerals $[1,2]$.

The development of the northern territories, from the standpoint of construction, involves the implementation of three global tasks. Firstly, the construction of buildings and structures providing heat saving, comfortable indoor conditions and the possibility of implementing technological processes (which also requires positive temperatures). Secondly, the development of road infrastructure, taking into account the preservation of permafrost. Thirdly, the design and installation of prefabricated modular structures and insulation systems for residential modules of polar vehicles [3, 4]. System solutions should

\footnotetext{
*Corresponding author: zinkate@mail.ru
} 
form heat-efficient and uniform insulating shells, ensure standard durability of structures as a whole, the comfort of residential premises and meet fire and environmental requirements.

\section{Experimental}

Insulation materials should have not only low thermal conductivity, vapor and water permeability, as well as resistance to aggressive environments during flooding, and at negative or alternating temperatures [5-7]. Products based on mineral wool in such conditions are undesirable. These products have high open porosity, which makes it possible to infiltrate air (especially at the junctions), high moisture capacity, and low resistance under conditions of humidification and alternating temperatures [8-10].

Foamed plastics, namely products based on extruded polystyrene foam (XPS-plates) and polyethylene foam (PE-products), are most suitable for the operating conditions under consideration. A feature of these products is the combustibility inherent in most synthetic polymeric materials.

XPS-boards have great rigidity and resistance to mechanical loads and are used in the construction of road base and facade systems with plastering (CFTK), for the insulation of floors, ceilings, in systems base of roads of various types and purposes. The experience of using such products has been tested for decades, including in permafrost. The most serious problem of coatings using these materials is the thermal engineering heterogeneity caused by heat losses at the joints and the infiltration of cold air through them [11-13]. Note that the greater the temperature difference (outside and inside the room), the more these losses are manifested.

Products based on polyethylene foam (PE - mats or rolls, with or without a reflective coating) have low heat, vapor and moisture permeability, high operational resistance and are flexible material that allows to insulate surfaces of complex configuration and allowing seamless welded joint. According to the above, the article considered insulation systems based on foamed plastics, developed taking into account their advantages and features.

The experiment was carried out according to the method developed by the National Research University of Moscow State University of civil engineering on the basis of joint research with the Vilnius Technical University named after Gedeminas (Lithuania), and the express methodology of the Higher School of Economics (GACIS) [17-19]. The basis of the methodology was the assessment of creep of samples of thermal insulation products. The samples were subjected to climatic influences in various regimes; after which their physical and mechanical characteristics were determined (GOST 17177-94), including their deformation curves, and then their creep under load was studied (GOST EN 1606-2011).

\section{Results}

The study of the properties of expanded polyethylene and extruded polystyrene foam, carried out according to the methodology of NRU MGSU and standard methods showed that these materials are characterized by constant properties in the temperature range from $60^{\circ} \mathrm{C}$ to $+70^{\circ} \mathrm{C}$, the influence of alternating temperatures and transitions through $0^{\circ} \mathrm{C}$, when holding materials in a climate chamber, to their operational stability does not significantly affect (within the permissible error of the experiment).

As a result of experiments, it was found that the samples were not damaged. A decrease in the strength characteristics of samples of polyethylene foam and extruded polystyrene foam after climatic tests does not exceed 4-6\%. The creep indices of products after climatic influences practically do not differ from the creep of control samples under normal 
conditions. The material can be recommended as a thermal insulation of objects operated at temperatures from $-60^{\circ} \mathrm{C}$ and above.

\section{Discussion}

The insulation systems of residential facilities for the Arctic have a number of significant features, the main of which are technologies that allow to preserve permafrost. Preservation of the soil in a frozen state involves either the use of floating foundations (like a "Swedish plate"), which is not effective for residential buildings (heat goes through the floor, the soil thaws and loses its bearing capacity), or construction on piles, used everywhere. Thus, in addition to the walls and the roof, an additional plane of heat loss is formed: the overlap above the ventilated basement, resting (naturally) through the grillage on the pile foundation.

The insulation scheme of a residential facility with a pile foundation is shown in Fig. 1 a. The insulation of the walls is carried out according to the technology of stucco facades with insulation (CFTK), and the overlap over the ventilated space is isolated by several layers of XPS-plates laid with offset joints.

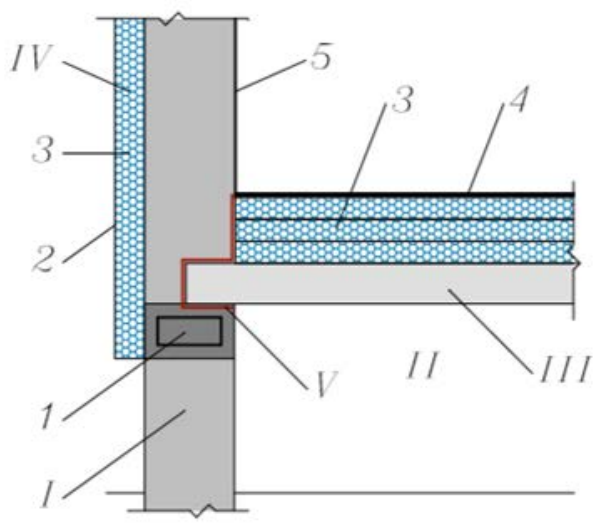

a)

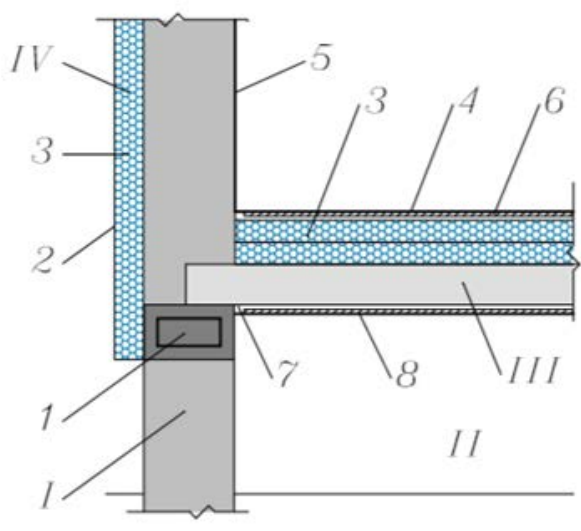

b)

Fig. 1. The scheme of overlapping a residential building: I - column; II - ventilated space; III- overlap over a ventilated space; IV - bearing wall; V - region of increased heat transfer and cold air infiltration; 1 - tying columns (fachwerk); 2 - system of facade insulation (SFTK); 3 - plate insulation; 4 - finish flooring; 5 - interior wall cladding; 6 - floating floor system (dry assembly); 7 - insulation over a ventilated space; 8 - protective lining

Such an insulation system has two negative aspects, these are cold bridges at the joints of plates (displacement during installation allows them to be minimized, but not completely), and most importantly, a serious heat transfer path between the joint of heatinsulating plates and walling (Fig. 1 a). This is not only an area of active conductive heat transfer, but also a way for infiltration of cold air through joint leaks. At significant negative outside temperatures (from $-30{ }^{\circ} \mathrm{C}$ and below), the perimeter of the building in its lower basement remains in the region of negative temperatures, which is extremely undesirable both from the point of view of room comfort and from the point of save of maintaining structures. At the same time, the thickness of the insulation laid on the floor can reach $500 \mathrm{~mm}$.

Experience in the use of foamed polyethylene in central Russia, and, not least, the implementation of the basic principles of the TEPOFOL LLC technology, based on the mechanical fastening of insulating sheets (rolls), joining them in a lock joint and welding 
these joints with hot air (using a building hair dryer), allowed to formulate recommendations on the formation of an effective insulating coating.

The resulting heat-insulating fabric is leak-proof, that is, there are no cracks and joints in it, which prevents the heat flow from coming out. Thus, in the obtained integral heatinsulating layer there are not completely no heat-conducting bridges along the surface, which has a positive effect on the characteristics of the entire insulating sheath. The proposed insulation technology, which is a proprietary product of the manufacturer of a rolled polyethylene foam heat insulator (TEPOFOL technology), provides heat preservation inside and significantly increases the heat-saving properties of the thermal insulation system [20-22].

Roll polyethylene foam with a reflective coating (foil or metallized lavsan) forms a protective layer along the outer perimeter of the structure (Fig. $1 \mathrm{~b}$ ), and is the basis of a floating floor laid on heat-insulating XPS-plates.

In accordance with the research system developed by NRU MGSU, NRU HSE and OOO TEPOFOL, taking into account the studies carried out by the NIISF RAASN, the insulation system of building structures operating in extremely cold conditions, the insulation shell is combined from XPS-plates and rolls or mats of polyethylene foam with metallized coating. The main heat-insulating material are XPS-plates with a stable lower thermal conductivity. Lamellas from facade mineral wool slabs are used as fire-fighting extensions and frames. PE products form heat-, steam-, and waterproofing membranes: on the outside of the ventilated space of the base with the mandatory closure of sheet noncombustible material with the overlap of all joints and indoors.

The inner insulating sheath is formed according to the principle of floating floor of dry assembly. Rolls of polyethylene foam are laid on the base (the metallized surface to the outside), placed on the walls, mechanically fixed around the perimeter, the joints are connected into a lock and welded with a construction hairdryer. Then lay chrysotile cement (most reliable) or fiber cement sheets (in two layers) and on them - the finish coating. Soundproofing of the base is carried out as an "additional bonus".

With a thickness of XPS-thermal insulation of $200 \ldots 250 \mathrm{~mm}$ and a total thickness of PE-insulation coating of $60 \mathrm{~mm}$, the thermal resistance of the insulation loop is at least 8.0 $\mathrm{m} 2{ }^{\circ} \mathrm{C} / \mathrm{W}$, while thermal uniformity of the construction increases and completely eliminates the path of infiltration of cold air.

When isolating mobile construction sites, residential modules, or caterpillar and wheeled tractors carrying personnel, it is necessary to insulate these rooms. A feature of the structures under consideration is the external metal shell. The thermal insulation used in this case must be flexible and vapor-tight, because otherwise, the vapor-air mixture condenses in the thermal insulation, drops in hoarfrost on metal, and the temperature in the insulated volume becomes stably negative, that is, unsuitable for survival.

According to the results of studies conducted at the NRU MGSU, a project was implemented to create isolated residential modules for tracked and wheeled vehicles, including mobile special equipment (Fig. 2). The basis of the seamless insulating sheath is steel rolls and sheets of foam with a metallized coating, welded at the joints with a building hair dryer.

The factors of heat saving and the formation of comfortable conditions in the premises (in terms of humidity, temperature, temperature difference between the wall and the room) are fulfilled to a greater extent with the implementation of additional engineering solutions. Installation of recuperators allows both to save energy and to provide optimal temperature and humidity conditions. Warm air from the room passes through the heat exchanger and heats the heat exchanger, and, on the return run, cold but clean and dry air from the street passes through the heat exchanger and enters the room. Such recuperators are 
recommended for residential premises, insulated modules, industrial facilities, sports facilities and warehouses. There is climate control is necessary.

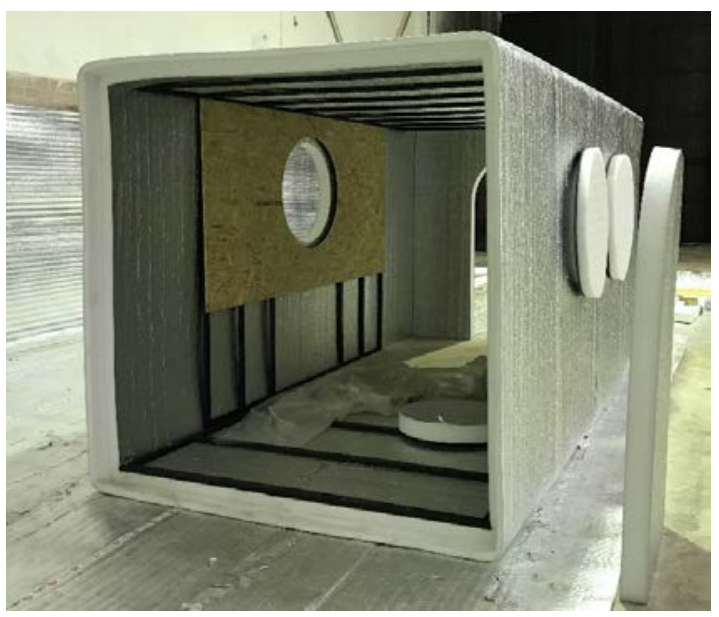

Fig. 2. Insulated module

Tests carried out during the Arctic expedition 2017-18 in the Republic of Sakha (Yakutia) showed that thermal insulation based on non-crosslinked polyethylene foam allows to provide for two months (or more) the viability of a residential module at an ambient temperature of minus $45^{\circ} \mathrm{C}$ and above at strong wind with gusts up to $30 \mathrm{~m} / \mathrm{s}$.

In the conditions of the far north and construction in permafrost regions, it is mandatory to regulate heat transfer in the road surface. At the same time, two main tasks are solved: preservation of the ground in a frozen state and a decrease in the mass of the road surface, that is, a reduction in ground loads, as well as protection of the main soil from excessive vibrations caused by traffic.

As part of the road structure, XPS-plates represent a shock-absorbing and temperature barrier between the layers of the roadbed and soil. These systems are especially in demand in three cases: when there are weak soils at the base; when construction is carried out on permafrost and when lightweight road structures are needed.

When laying roads there are found with weak soils. More than $60 \%$ of roads are built on floodplain sections of rivers, where wetlands, consisting of soft soils, are most often found. Weak soils include cohesive soils having a shear strength under natural occurrence of less than $0.075 \mathrm{MPa}$ (when tested with a rotary cut device) or a settlement modulus with a load of $0.25 \mathrm{MPa}$ more than $50 \mathrm{~mm} / \mathrm{m}$ (deformation modulus below $5 \mathrm{MPa}$ ). In the absence of test data, weak soils should include: peat and peat soils, silts, sapropels; clay soils with a consistency coefficient of more than 0.5 ; soils of wet solonchaks.

In the conditions of permafrost, the construction of heat-insulating layers (from XPSplates) allows you to keep permafrost soils in a natural state, which prevents thawing and eliminates subsidence of the subgrade, that is it provides stable and reliable operation of the foundation of the subgrade constructed in the conditions of permafrost propagation (Fig. 3).

Light embankments are called embankments which, for the same geometric dimensions, have a much lower specific gravity per $1 \mathrm{~m} 3$ of embankment due to the content of materials having a significantly lower specific gravity compared to soil. Thereby, a significant decrease in the embankment pressure from its own weight on the base is achieved. This allows you to build a light embankment without additional measures to strengthen the soil.

One of the modern materials with a minimum specific gravity are XPS-plates. The construction of light (lightweight) embankments from XPS blocks during the construction 
of roads and other engineering structures on a weak foundation is a promising area of road construction (Fig. 4).

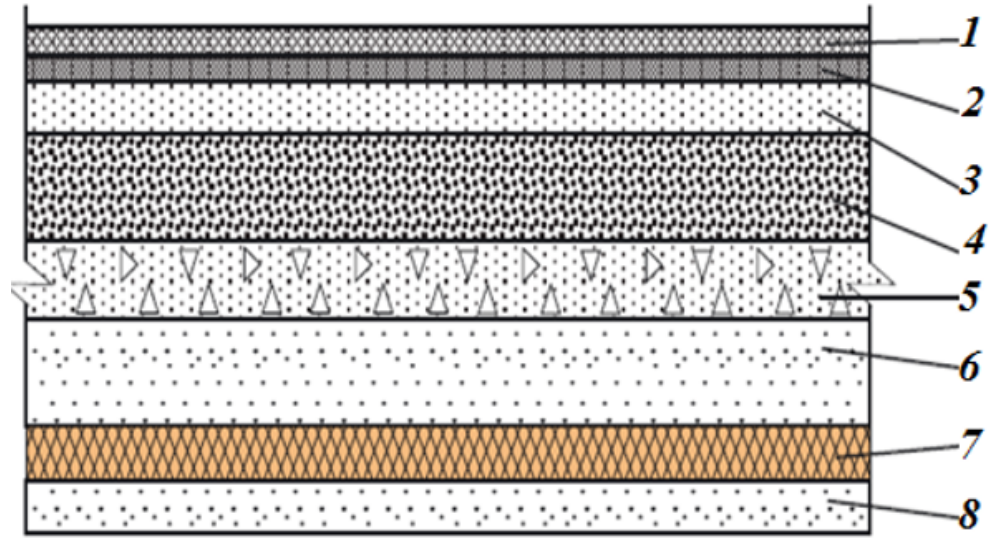

Fig. 3. Road insulation system diagram; 1, 2 - dense asphalt concrete; 3 - porous asphalt-concrete; 4 crushed stone-sand mixture reinforced with cement; 5 - embedding crushed stone M400; 6 - sand; 7 XPS-plates; 8 - leveling sand

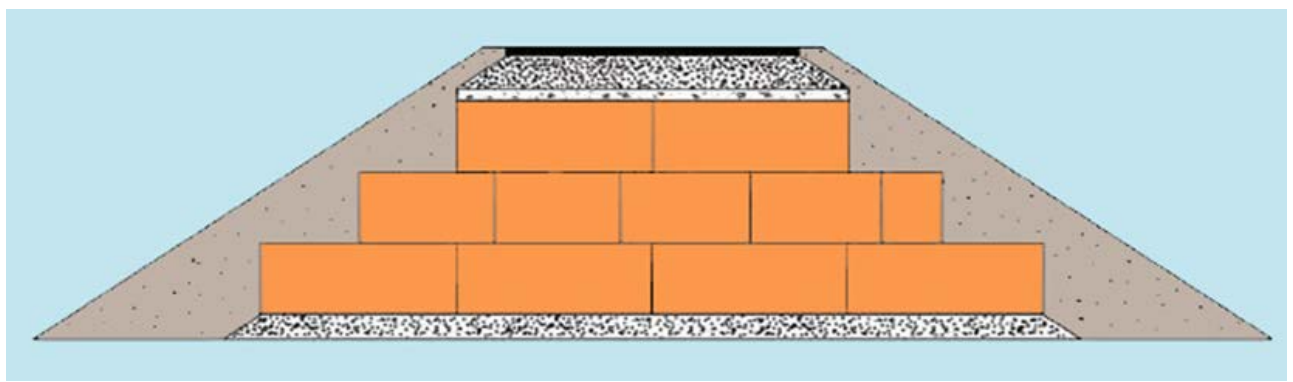

Fig. 4. Schematic diagram of the light embankment

\section{Conclusions}

The study of the properties of expanded polyethylene and extruded polystyrene foam, carried out according to the methodology of NRU MGSU and standard methods showed that these materials are characterized by constant properties in the temperature range from $60^{\circ} \mathrm{C}$ to $+70^{\circ} \mathrm{C}$, the influence of alternating temperatures and transitions through $0^{\circ} \mathrm{C}$, when holding materials in a climate chamber, to their operational stability does not significantly affect (within the permissible error of the experiment).

In conditions of low temperatures and strong winds characteristic of the northern territories, it becomes necessary to use complex insulation systems that provide both high thermal resistance, heat engineering uniformity, and durability of structures. In this regard, it is advisable to use materials as a heater, on which negative and alternating temperatures and non-constant humidity have the least effect. Such materials include foamed plastics and, in particular, foamed polyethylene and extruded polystyrene, the appropriateness of which is confirmed by both laboratory and field tests, as well as experience in the construction of objects for various functional purposes. 


\section{References}

1. A. Zhukov, E. Bobrova, D. Zelenshchikov, R. Mustafaev, A. Khimich, Insulation systems and green sustainable construction, Advanced Materials, Structures and Mechanical Engineering. v.1025-1026, pp. 1031-1034 (2014).

2. V. Gagarin, V. Kozlov, Mathematical model and engineering method for calculat-ing humidity condition of constructions, Academia. Architecture and engineering. № 2, pp. 60-63 (2006).

3. V. Gagarin, Macroeconomic aspects of the substantiation of energy saving measures by increasing the thermal protection enclosing structures of buildings, Construction materials. №3, pp. 8-161 (2010).

4. P. Zhuk, A. Zhukov, Normative legal base of environmental assessment of build-ing materials: prospects for improvement , Ecology and industry of Russia. № 4, pp. 5257 (2018).

5. I. Bessonov, A. Starostin, V. Oskina, Dimensionally stable fiber insulation, Vestnik MSUCE №3, pp. 134-139 (2011).

6. B. Rumiantcev, A. Zhukov, D. Zelenshikov, A. Chkunin, K. Ivanov, Yu. Sazonova, Insulation systems of the building construtions, MATEC Web of Conferences. v. 86 (2016). DOI: 20168604027.

7. B. Rumiantcev, A. Zhukov, E. Bobrova, I. Romanova, D. Zelenshikov, T. Smirnova, The systems of insulation and a methodology for assessing the durability, MATEC Web of Conferences. v. 86 (2016). DOI: 20168604036.

8. N. Umnyakova. The environmental impact of the urban environment on the construction of ventilated facades, Vestnik MGSU, № 4. v.5, pp. 157-162, (2010).

9. N. Umnyakova, The relationship of the ecological state of cities and durability of building materials and structures, Housing construction. № 1, pp. 30-33 (2012).

10. V. Hlevchuk, I. Bezsonov, On current thermal performance of mineral wool, Problems of construction of thermal physics, climate systems, and energy efficiency in buildings, pp. 127-135, (1998).

11. S. Shmelev, Ways of selecting the optimal set of energy-saving measures, Construction materials, №3, pp. 7-9, (2013).

12. E. Arquis, C. Cicasu, Convection phenomen in mineral wool in-stalled on verti-cal walls, Proceedings of the International scientific-practical conference «Effective heat and sound insulating materials in modern construction and housing and communal services», pp. 18-21. (2006)

13. N. Umnyakova, Climatic parameters of a typical year for heat engineering engineering calculations, Bulletin of construction equipment, № 8. pp. 45-50, (2016).

14. D. Tuchaev, E. Zarmanyan, E. Petrovskiy. A. Zemlyanko K. Ivanov, A. Zhukov, Thermal insulation systems for the Arctic, IOP Conf. Series: Materials Science and Engineering, doi:10.1088/1757-899X/365/3/032015032041 (2018)

15. Patent for Russian Federation invention no. 2645190 «lock technology of thermal insulation material for seamless welding of connecting locks», registered on February 16th, 2018.

16. A. Zhukov, K. Ter-Zakaryan, V. Semenov, Insulation systems with the expanded polyethylene application, ScienceDirect IFAC PaperOnLine, v.51, № 30, pp. 803-807 (2018). DOI: 10.1016/j.ifacol.2018.11.191. 
17. I. Gnip, V. Kerchulis, S.Vaitkus, Confidence intervals forecasting creep defor-mation of foam polystyrene, Stroitel'nye materialy, № 12, pp. 40-44 (2012).

18. I. Gnip, V. Keršulis, S.Vaitkus, Analytical description of the creep of expanded polystyrene under compressive loading, Mechanics of Composite materials, No 41(4), pp. 357-364 (2005).

19. A. Zhukov, V. Semyonov, I. Gnip, S. Vaitkus, The investigation of expanded polystyrene creep behavior, MATEC Web of Conferences, v. 117, (2017)

20. A. Zhukov, K. Ter-Zakaryan, I. Bessonov, V. Semenov, A. Starostin, Systems of building insulation with the use of polyethylene foam, Construction materials, № 9, pp. 58-61 (2018).

21. A. Zhukov, V. Semenov, K. Ter-Zakaryan, Yu. Sazonova, Features of the implementation of insulation systems in the Far North, Construction materials, №.4, pp. 65-69 (2018).

22. A. Medvedev, E. Bobrova, A. Poserenin, E. Zarmanyan, Evaluation of mineral fiber properties using $x$-ray fluorescence analysis and measurement of natural radioactivity, (2018) DOI: 201817003018 